\title{
Frontline Healthcare Staffs' Experience of Organising Complex Hospital Discharges: An Ethnographic Study
}

\section{Alexandros Georgiadis, Oonagh Corrigan \& Ewen Speed}

To cite this article: Alexandros Georgiadis, Oonagh Corrigan \& Ewen Speed (2016): Frontline Healthcare Staffs' Experience of Organising Complex Hospital Discharges: An Ethnographic Study, Ethics \& Behavior, DOI: 10.1080/10508422.2016.1200977

To link to this article: http://dx.doi.org/10.1080/10508422.2016.1200977

Accepted author version posted online: 20 Jun 2016.

Published online: 20 Jun 2016.

Submit your article to this journal $₫$

Llll Article views: 31

View related articles

View Crossmark data $\nearrow$ 


\title{
Frontline Healthcare Staffs' Experience of Organising Complex Hospital Discharges: An Ethnographic Study
}

\author{
Alexandros Georgiadis ${ }^{1 *}$ Oonagh Corrigan $^{2}$ Ewen $_{\text {Speed }}^{3}$ \\ ${ }^{1}$ Research Associate, Healthwatch Essex email: alex.georgiadis@ healthwatchessex.org.uk \\ (corresponding author) \\ ${ }^{2}$ Research \& Commissioning Manager, Healthwatch Essex, email: \\ oonagh.corrigan@ healthwatchessex.org.uk \\ ${ }^{3}$ Senior Lecturer, University of Essex, Colchester Campus \\ email: esspeed@essex.ac.uk
}

\begin{abstract}
Existing studies show that nurses often experience moral distress when the care they deliver to patients does not meet their professional values. We draw on ethnographic data collected in June 2015 from one acute care trust in England and present how frontline healthcare staff experience organising complex hospital discharges. Our findings demonstrate how problems with the panel responsible for allocating funding for NHS continuing healthcare cases contributed to healthcare staff experiencing moral distress. Our findings offer a basis for further research on how other aspects of the complex hospital discharge planning process may contribute to nurses' experiencing moral distress.
\end{abstract}

\section{Keywords}

discharge facilitators; nurses; continuing healthcare; moral distress; England.

An increasing literature has examined the value-conflicts that healthcare professionals experience at their workplace, such as the provision of low quality care and maltreatment of 
patients, which can cause them to experience moral distress (Corley, 2002; Hanna, 2004). Moral distress "occurs when an individual identifies the ethically appropriate action but that action cannot be taken" (Epstein \& Delgato, 2010). Within the healthcare team, one's inability to carry out an action could be attributed to internal (i.e. fear of losing a job, anxiety) or external factors (i.e. power imbalances between team members, pressure to reduce costs) (Jameton, 1993). Moral distress is a multi-disciplinary problem that has been explored in a range of professions, such as nursing (Epstein \& Hamric, 2008), physicians (Chen, 2009) and pharmacists (Sporrong, Hoglund, Hansson, Westerholm \& Arnetz, 2005). Moral distress is different from the concept of emotional distress which does not necessarily involve an ethical element (McCarthy \& Deady, 2008).

Schluter, Winch, Holzhauser and Henderson (2008) identified three causes that can contribute to moral distress to nurses: poor-quality and futile care, unsuccessful advocacy, and raising unrealistic hope. In relation to the first cause, nurses report moral distress due to staff shortages, resulting in bad quality care for patients. Unsuccessful advocacy refers to nurses being unable to achieve the best outcomes for their patients, often due to confrontation or lack of respect from physicians. Finally, nurses report moral distress when the medical team provides the patients and their families with inaccurate or incomplete information about treatment and prognosis. Whereas some authors report that moral distress does not impact negatively on the provision of care, other authors report that it does (Gallagher, 2010). These authors report that moral distress often results in nurses leaving their jobs or profession (Schluter et al., 2008). 
A survey conducted by the Royal College of Nursing (2008) found that $70 \%$ of the nurses left work sometimes feeling distressed, and $11 \%$ left work always feeling distressed, because they could not provide the type of care they knew that they should provide. These findings indicate that nursing is neither practiced in a vacuum nor that is rests on the responsibility of the individual nurses (micro level). Organisational (meso level) and political (macro level) factors can affect the care that nurses provide (Gallagher, 2010).

With regard to hospital discharge, existing studies show that nurses and/or discharge facilitators often experience difficulties in planning discharge-related care (Bauer, Fitzgerald, Haesler \& Manfrin, 2008; Rose \& McCarthy, 2009). For instance, Nosbusch, Weiss and Bobay (2010) wrote an integrated review of the literature on the challenges confronting the acute care staff in discharge planning. They identified interrelated themes across the literature: 1) poor communication (both verbal and written), 2) lack of systems and structures, 3) limited time to plan proper care, 4) role confusion, 5) care continuity, 6) nurses' lack of knowledge regarding community resources and services, and 7) invisibility of registered nurses role in discharge planning. These themes illustrate the level of systemic complexity that characterizes the discharge planning process.

Findings from other international studies concur with the findings reported by Nosbusch et al. (2010). For example, in Taiwan, Chang et al. (2015) found that discharge planning is a neglected issue in the ED (emergency department), and that heavy workload and the negative attitudes of ED patients and their families have a negative impact on nurses' experience of the process. Similarly, in Australia, a study by Kable, Chenoweth, Pond and Hullick (2015) demonstrates that 
nurses experience pressures to quickly discharge patients and face obstacles with post-discharge services as demand for places exceeds availability.

Swedish studies also confirm these findings. For example, Ekdahl, Linderholm, Hellstrom, Andersson \& Friedrichsen (2016) suggested that nurses are preoccupied with freeing up beds which led to failing to meet the high needs of elderly patients and this also generated feelings of guilt and frustration in the staff and contributed to making the patients feel unwelcome. Augustinsson and Petersson (2015) report that discharge planning is a dynamic complex process, and that nurses have to navigate through uncertainty, surprises, and manage complex relations and information in the discharge planning process. In Iran, Gholizadeh, Delgoshaei, Gorji, Toram and Janath (2016) show how a range of factors from different areas, such as leadership/governance (i.e. lack of systematic approach, lack of structure and management, lack of communication and advocacy), service delivery (i.e. poor structure, lack of attitude and standards), information (i.e. poor facilities and training), financing, health workforce (i.e. lack of empowerment, motivation and management), and medical production (i.e. lack of infrastructure) pose barriers in developing effective discharge planning. These findings indicate that discharge planning is a complex hospital function; however, they also indicate that discharge planning processes can contribute to ethical dilemmas, as often nurses are diverted from taking care of patients to administrating patients and beds.

The previous health services research literature has examined how nurses working in medical wards (Armitage \& Kavanagh, 2007), emergency wards (Han, Barnard \& Chapman, 2009), and ICU wards (Chaboyer, Foster, Kendall \& James, 2004) experience the discharge planning 
process. Furthermore, the literature shows that when healthcare professionals face ethical dilemmas with regard to the type and level of care they provide to patients, they may experience moral distress. As the number of frail older people with chronic, multiple and complex care needs is increasing, it is expected that the number of complex discharges will follow a similar trend (Hendy, Patel, Kordbacheh, Laskar \& Harbord, 2012). It is therefore essential to determine how frontline healthcare staff experience organizing complex hospital discharges in order to avoid experiencing moral distress and identify strategies that need to be implemented to ensure best practice and improve patient experience.

\section{Background}

Hospital discharge planning has received much attention nationally and internationally, because of the rising healthcare costs linked to the management of acute and chronic illnesses, the trend towards shorter hospital stays, and the ageing population (Coleman, 2003; Department of Health [DH], 2010). Evidence also suggests that timely and safe discharge benefit both the patients and the healthcare system, as it improves patients' health, decreases the risk of infection and loss of independence and reduces readmission rates (Phillips et al., 2004; Preen et al., 2005). The importance of discharge planning in the acute and sub-acute healthcare policy and practice is mirrored in the development and implementation of guidelines that outline good practices in hospital discharge planning processes (Wong et al., 2011). For example, Wong et al. (2011) report that in the United States and Australia discharge planning is a legally mandated 'basic' hospital function and tends to be underpinned by a trend to start discharge planning upon admission based on a multi-disciplinary approach and extend it to post-discharge care support. 
In the UK, hospital discharge planning is underpinned by similar trends (i.e. initiate discharge planning upon admission based on multi-disciplinary work), whilst also emphasising the need for a clear focus on freeing beds and on finding alternative ways of discharging patients (DH, 2000). The exponential decrease of social care authorities' budgets and the squeezing of the NHS (National Health Service) spending have placed considerable pressure upon several care areas including hospital discharges (NHS Confederation, 2012; The Health Foundation, 2015). The consequences of the spending cuts, among others, include the closing down of care/nursing homes and the recruitment of agency nurses. Such issues may have implications for both the patients and the NHS; firstly, patients stay longer in the hospital, which, increases NHS costs and patients' risk for infection, and secondly, owing to the lack of permanent nursing staff, patients' personal continuity of care is fragmented, which impacts negatively on patients' experience of care.

In addition to the wider structural and political problems that affect the discharge planning process, the literature indicates a range of organizational factors that can negatively influence professionals and patients' experience of hospital discharge in England. For instance, some authors report the presence of recurring problems in the interface between primary and secondary care at the time of discharge (Day, McCarthy \& Coffey, 2009; McKenna, Keeney, Glenn \& Gordon, 2000), such as poor communication between professionals and services within primary and secondary care organisations, and the lack of a whole systems approach in discharge planning (DH, 2003). In their study on healthcare professionals experience of discharge planning Connolly et al. (2009) report that, owing to pressures for short hospital stays and rapid discharges, nurses have limited time to discuss discharge issues with patients, which can 
negatively affect discharge preparation and planning. Additionally, Effraimsson, Sandman, Hyden and Rasmussen (2004) describe hospital staff as engulfed in a 'praxis of bureaucracy' (p. 576) which impedes their flexibility, and thus, their professional autonomy in discharge planning. Further, Connolly et al. (2009) report that hospital staff are not formally trained in discharge planning, but are taught about discharge on the job; therefore, hospital staff may not consider discharge planning as a priority, which can result in transferring the responsibility to junior staff who carry it out with limited or no support from more senior staff. Although useful in understanding the challenges that hospital staff face in discharge planning, the wider literature has not examined how hospital staff experience complex discharge cases.

The term complex discharge refers to discharges that involve patients who will be discharged to their home or residential home or intermediate care or nursing home and have complex ongoing health and social care needs which require detailed assessments, planning and delivery by multiagency working or multi-disciplinary team and their length of stay in hospital is difficult to predict (Currie \& Watterson, 2008). For example, a complex discharge would involve a patient who experiences one (or more) physical health problem (i.e. cancer) which has affected her ability to perform on her own accord everyday tasks, such as personal hygiene, ability to eat and drink, and take her medicine. To discharge this patient from the hospital to her home (or care/nursing home), the complex discharge team (i.e. discharge facilitators) has to match her care needs with the services available in the community. Complex hospital discharges are not rare and, some of them, pose challenges to patients and care authorities owing to their high healthcare costs. 
NHS continuing healthcare is a name that has been given to a care package organized and funded solely by the NHS for individuals living in the community with ongoing care needs. Individuals can receive continuing healthcare either in the homes or in a care home (DH, 2012). The DH has developed screening tools that assist the discharge facilitators (i.e. often comprised by senior nurses and social workers) in assessing whether inpatients are eligible to have their costs paid in full by the CCG (Clinical Commissioning Groups - these are local GP led commissioning groups responsible for NHS commission of services) in order to transfer their care to community-based services (DH, 2012, 2012a).

Typically this involves assessing whether a patient's illness has reached a terminal phase (assessed via the 'Fast Track assessment for End of Life Care - EoL), or they have complex and high levels of care needs (assessed via the Decision Support Tool for NHS continuing healthcare). A panel (the continuing healthcare panel), which is part of the CCG, has the ultimate responsibility for deciding whether patients meet the criteria, and therefore, whether the CCG needs to fully fund their care. Persons who do not qualify for either of these care packages often become the responsibility of social care services, and under current UK legislation, may be required to contribute towards the cost of their own care irrespective of the level and cost of their care needs (Health and Social Care Act, 2012). Figure 1 presents a process diagram of the complex discharge planning process.

Insert figure 1 here

\section{The study}




\section{Design}

This paper is based on an ongoing mixed-methods study of the hospital discharge process taking place in three hospitals in Eastern England (report forthcoming, Corrigan et al. 2016). Data were collected from June 2015 to October 2015 through participant observation, semi-structured interviews and surveys. We interviewed members of the complex discharge team, ward staff (i.e. a consultant and nurses), and patients and their carers who had experience in complex discharge planning. The findings presented in this article are drawn from an analysis of a subset of data (from one hospital trust) from this larger study. We chose this sub-set of data based on our aim to provide a more nuanced understanding of how frontline healthcare experience organising complex hospital discharges.

Ethnography, the research method that we adopted for this segment of the study, offers a means to investigate the social interactions, behaviours, and perceptions that occur within groups, teams, organisations, and communities (O'Reilly, 2005). Ethnography is a form of qualitative research that combines methods, such as interviews and participant observation (Fielding, 1994). This method is widely used in health care research (Taxis \& Barber, 2003), and it is particularly suited for the study of organisational processes and work cultures (Waring et al., 2014). We chose this method in order to increase our understanding on how frontline healthcare staff experience organising complex discharges within the current policy and organisational context of care in England. The emphasis in ethnography is on 'depth', 'intensity' and 'richness' and hence a large number of participants is not necessary (Fielding, 1994). 


\section{Participants}

The aim of the study was to examine how frontline healthcare staff experience organising complex hospital discharge cases. Therefore, we approached and recruited care professionals who were working in the complex discharge team. In order to elicit a broad range of perspectives on the issue, we aimed to recruit discharge facilitators that had either little or much experience in complex discharge planning and were part of either the health or the social care team. We recruited a purposeful sample of seven health and social care professionals working in the complex discharge team. In order to get a deeper picture of how care professionals experience organising complex hospital discharges, we also aimed to identify ward-based healthcare professionals experienced in organising complex discharges. Therefore, we recruited one consultant (based on an elderly care ward) with experience in organising complex hospital discharges. Table 1 presents participants' details. Prior to the interview, all participants signed an informed consent and were informed of their right to withdraw from the study without any consequences. Participants did not receive any compensation for their participation.

\section{Data collection}

The data for this hospital was collected in June 2015, using interviews and recording fieldnotes through participant observation. The interviews utilised a semi-structured format, and they were primarily reflexive and were focused on how participants experienced the complex hospital discharge planning process. The interview took the form of a 'guided conversation' (Lofland \& Lofland, 1995) where information was elicited in a naturalistic way. Table 2 presents the topics 
that were covered during the interviews. All interviews were carried out in private rooms and lasted approximately 20-30 min; all interviews were audio recorded and transcribed verbatim.

The ethnographer and the lead author Alexandros Georgiadis (AG) observed the staff and shadowed them during their working day and recorded fieldnotes of the daily routine of the discharge team during week-days. For example, AG shadowed the discharge facilitators in board rounds (morning meetings in the wards where health and, often social care, professionals discuss the progress of the patients) in the wards, meetings with patients and their families, and interactions with health and social care staff. To minimise his impact on the research process, AG explained to the participants that his aim was to understand the complex discharge process rather than to evaluate their work performance.

\section{Ethical approval}

The study requested and received ethical approval from a NHS ethics committee (NRES Committee East Midlands - Nottingham 1, REC ref: 15/EM/0070) and local Research and Development departments. Access to the hospital was negotiated with the senior management team and the manager of the discharge team.

\section{Data analysis}

The interview and observation data were subjected to inductive thematic analysis (Braun \& Clarke, 2006). Braun and Clarke (2006) argue that thematic analysis does not need pre-existing themes in order to proceed with the analysis. Every statement is considered as valid in gaining a 
deeper insight into a single or multiple concepts. Further, the fact that thematic analysis is not embedded in any ontological or epistemological paradigm makes its use more flexible. Table 3 shows the steps that we followed to analyse the data. The data were analysed using the NVivo 10 computer software program.

\section{Trustworthiness}

The second author and principal investigator of the study (OC) acted as a second coder to ensure inter-rater reliability following Noble and Smith's (2015) guidelines on rigour in qualitative research. The limited number of disputes over different interpretations was resolved through discussion and re-examination of the data.

\section{Findings}

The analysis of the collected data resulted in the development of two themes that describe how participants experienced organising complex hospital discharges. Problems with the panel responsible for allocating funding to 'continuing healthcare' cases were reported to be the biggest barrier to affect complex discharges.

\section{Discharging with limited resources}

Discharging patients with complex needs but with limited resources was one of the key themes identified in both the participants' narratives and the ethnographer's fieldnotes. We use the term resources in its broadest sense to include all the human and non-human capital that the discharge 
team has at its disposal to facilitate the safe and timely discharge of patients. The issue of limited resources, both in and out of the hospital, posed several challenges to the discharge team and, therefore, had often a negative impact on complex discharge planning.

Problems with community care services, and in particular with patients' eligibility to receive NHS continuing healthcare was a central issue in participants' narratives. Participants reported that their daily clinical work was challenged, as there were inconsistencies around the ways that the panel applied the 'continuing healthcare' criteria to assess patients' eligibility to have their care funded in the community. Through informal discussions with staff, AG noted their perplexity with regard to how the panel was applying the criteria on their assessments. These staff appeared to suggest that patients with almost similar care needs and prognosis would now not get funded, even though in the past other patients with similar care needs and prognosis had been allotted funding. As one health worker reflected:

"For us personally, I think the funding options at the moment is very difficult because, as you know, a lot of people that we would have referred for fast track funding and would have got it a year ago are now not getting it. So it puts a lot of strain on our team, a lot of strain on the ward and it's quite difficult for the families and the relative to understand that someone's dying but they are not entitled to full NHS funding."

(Interview, health care 1)

Many participants reported that they felt powerless to change the panel's decisions, and felt distraught by the high number of patients that, against their wishes, died in the hospital. Not 
being able to deliver the type and level of care that these patients needed, appeared to trigger a range of emotional reactions to both the discharge team and the ward staff. AG observed that the morale in the discharge team appeared to be low as a result of their perceived inability to improve a process that they described as unfair.

"I was sitting in the discharge office with [names of discharge staff]. They told me that the staff's morale was really low because of the difficulties they faced with the discharge process, particularly with the high rates of $\mathrm{CHC}$ rejections. Also, I felt that many members of the discharge team felt powerless in front of the decision-making practices of the CHCs. This experience appeared to increase the negative impact of the whole process in their emotional wellbeing."

(AG, field notes, June 2015)

AG noted that, in their informal discussions and team meetings, participants kept referring to the unethical dimension of the panel decision, which they felt operated as a barrier to facilitating patients to experience a good death in their homes surrounded by family and friends. Many participants described this aspect of their job as unsatisfactory, and therefore, a factor that had led them to start looking for other positions within the hospital.

Often the care needs of the deferred patients were too complex to be cared for by their families, and as such, many of them were redirected to the social care team to source a care package and ensure they were discharged as soon as possible. This transfer of responsibility caused some tensions within the discharge team, as the small size of the social care team coupled with their 
increasing caseload resulted in an increasing pressure to their workload. Participants reported that social workers were unfairly criticised for delaying discharges by the senior management team, patients' family members, and often, by their health care colleagues.

“Then it puts pressure on social care because they've got a time frame where they've got to try and organise care for someone that's ultimately, not long left to live. So that's really challenging for our team, personally, since about October now."

(Interview, health care 4)

Participants also reported that discharges were delayed because the social care team was short staffed, and hence, it could not keep up pace with the high volumes of discharge notifications that it received. Also, owing to its limited capacity, the social care team could not cover all the wards (i.e. attend the board rounds), and hence, if the delegated social worker of the ward was on leave, another social worker could not cover that ward. On many occasions social workers had to 'jump' between cases, which led to variation in levels of service, as they contributed to facilitating some discharges but delayed many others. The staff were aware of this problem, for example, one social care worker stated:

"I know I'm not going to be here until next Tuesday and there isn't anybody to cover...So it's challenging because I know today I'm trying to take measures to ensure everything is as up to date as it can be."

(Interview, social care 3) 
Participants also talked about the impact of staff shortages on the wards and the limited number of therapists and doctors available as well as the recruitment of agency/bank nurses and linked them with delayed discharges. Such issues created obstacles in complex discharge planning, as patients could not be discharged either because the therapists had not finished their interventions with them, or the doctors did not have time to review patients' discharge summaries, or the agency/bank nurses were not familiar with the needs of the patients, and hence, they were able to provide little or no input to the health and social care assessments. Further, participants reported problems with the care homes. Firstly, there were a few care/nursing homes available in the local area, and secondly, care/nursing homes varied in their responses to accepting referrals; some care/nursing homes would trust the assessments carried out by the hospital team, but others would not. Consequently, many patients experienced delayed discharges as they had to wait until a care/nursing home placement was available and/or they had to wait several days until some care/nursing home had carried out their assessments. Problems with care/nursing home providers coupled with the complexity of patients' needs posed significant challenges to the discharge team to source care for some patients. These challenges increased the number of patients who were medically fit to be discharged, but they were still in the hospital; for example, the consultant reflected:

"Participant: Yes. At any one time on any ward there are, you know I would say up to 50\% or more patients who may be medically fit for discharge.

Interviewer: Up to $50 \%$ ? 
Respondent: Yes, yes, easily, easily...But as I said, things are better but it could be even better if we had more resources to get these patients seen and get them out."

(Interview, consultant)

The processes presented above had a significant influence to the type and quality of care that patients received. Many patients experienced delayed discharges, and others, against their wishes died in the hospital ward.

\section{Variations in knowledge sharing and communication}

Another key theme in participants' talk around complex discharge planning was the variation in the ways that knowledge was shared within the discharge team, and between the discharge team and the wards and how they communicated with each other. Despite the initial challenges, many participants reported that co-locating the health and social care teams strengthened collaborative work and knowledge sharing between them. However some participants reported that the professional division between health and social care influenced the ways that they communicated and collaborated with each other. Despite the spatial integration, the health and social care teams described each other as distinct organisations that worked under different rules and regulations. The underlying organisational fragmentation of the discharge team appeared to contribute to differences on how each team viewed the needs of the patient. For example, one staff member reflected:

"At our level here, the team interact very, very well. Moving into the office was a very difficult way forward because obviously we were very segregated. Even just a move into an office was 
fraught with its own complexities, which you would expect sometimes. For me, it's been a positive experience, but we have a long way to go to develop. We are integrated in a sense of in the office and there is a lot of joint work going on, but we are still very fragmented.”

(Interview, social care 2)

AG also observed that knowledge sharing and communication was problematic between the discharge team and the ward staff. Processes that had been established to facilitate knowledge sharing did not work or partially worked, and communication on discharge planning processes was frequently partial and incomplete. In the mornings there are ward 'board rounds' and these are often seen as a good opportunity to exchange and share information (which indeed it was), but AG noted variations between wards on how well focused their board rounds were on complex discharge planning. In some wards the staff used the board round as an opportunity to share knowledge and facilitate discharge planning, whilst on other wards the staff appeared less involved in discharge planning, and the board rounds were used primarily as an opportunity to exchange information regarding patients' health needs, and not as an opportunity to plan ahead for their care needs upon discharge. AG observed that the level of involvement of each ward staff in discharge planning was dependent on the person who was in charge of the ward on the day of observation.

"Yesterday, [name of discharge facilitator] told me that [name of nurse] is involved in discharge planning. When we went today to the same ward another nurse was in charge who, according to [name of discharge facilitator], was not willing to get involved in discharge planning activities." 
(AG, field notes, June 2015)

Inconsistent practice and poor communication between the ward staff and the discharge team impacted negatively patients and their families' experience of discharge. For instance, many participants highlighted the fact that patients and their families often received contradictory information about their discharge planning from a range of different sources.

"Doctors will say one thing. We went through a spate where all the doctors were going, "This person's palliative, this person's for fast track, this person" and they were telling families and telling the patients that they would get full funding, but then the fast track was getting rejected and they were going via social care. That was causing a few complaints and a few problems from our point of view because we're the discharge team, we're the ones that make that recommendation, not the consultants."

(Interview, social care 2)

The example that the participant provided above, illustrates the confusion that patients' and their families could experience in their interactions with hospital staff; whereas one healthcare professional supported the view that a patient should receive palliative care, that is that the provision of psychological, social and spiritual support alongside the management of patient's pain, another healthcare professional believed that the patient should receive end-of-life care, that is the patient faced imminent death, and therefore, the patient needed to be discharged as soon as possible to die at her preferred place of death. Of course, healthcare professionals can have different opinions; however, the problem for our participants was that both professionals 
communicated their opinions to the families of the patients, without even consulting the complex discharge team, therefore creating much confusion to the families, and tensions between different groups of professionals in the care setting.

The extent to which the ward staff had been exposed to discharge planning activities and their knowledge of discharge-related care appeared to influence the communication between the discharge team and the ward staff. The challenge for the discharge team was on how to handle the increased expectations of patients and their families, since both appeared to more readily trust the doctors' opinion rather than the opinion of the discharge facilitator. It also appeared that ward staffs' limited knowledge of discharge planning and the lack of a discharge facilitator being continuously present in the wards, contributed to problematic knowledge sharing and communication in the wards. Noticeably though, knowledge sharing and communication between the discharge team and staff worked better in some wards not because the latter had more knowledge on discharge planning or they had a dedicated discharge facilitator based on their wards. AG noted that knowledge sharing and communication worked better for a small proportion of ward staff and discharge facilitators, because these ward staff viewed the discharge team as a 'tool' that they could use to facilitate the smooth running and management of the ward. In these working relationships AG noted that professionals had recognised the role of the discharge facilitator which, facilitated knowledge sharing and communication.

\section{Discussion}


Our objective in this paper was to explore how frontline healthcare experience organising complex hospital discharges. Our findings highlight the difficulties in providing personalised and continuing healthcare in an under-resourced and fragmented healthcare system. These findings were similar to that of Cheek and Gibson (2003) who found that limited resources and fragmented services challenge the provision of continuing healthcare. Indeed, participants talked about how the limited resources available in the hospital and in the community had a negative impact on complex discharge planning activities. Noticeably, many participants talked about the way the panel applied the eligibility criteria for NHS continuing healthcare. They described the panel's decision as unfair and appeared to be upset for being powerless to change their decision and provide the level and type of care that they deemed appropriate for the patient.

Participants' experience of 'continuing healthcare' cases appeared to resonate with the concept of moral distress (Epstein \& Delgato, 2010). Our participants talked about their distress at not being able to fulfil patients' wishes to die in their homes. In line with previous research (Schluten et al., 2008), our findings indicate that our participants often experienced moral distress because of their inability to successfully advocate for their patients to receive the kind and level of care they needed. Participants' experience of moral distress though was not rooted to confrontations with hospital physicians, but rather it was rooted in the bureaucratic challenges they experienced from the 'continuing healthcare panel'. Our participants reported that they could provide neither support patients' autonomy nor provide personalised and holistic care in relation to 'continuing healthcare' cases, and in particularly for patients whose illness had reached a terminal phase and wanted to be transferred to the community. Participants reported being unable to manage facilitating patients to experience a good death, that is a death that 
"encompass[es] no suffering (both from physical and psychosocial distress), dying at a preferred place, being around family, not being a burden to others and a 'sense of completion of their familial responsibilities during the last days of life" (Vencatasalu, Clarke \& Atkinson, 2015, p. 1677). Although previous research has demonstrated the interplay of patient and system related factors on transferring patients from critical care home to die (Coombs, Long-Sutehall, Darlington \& Richardson, 2015), our analysis shows that wider structural factors frequently contribute to difficulties in organising such complex discharges (Ingleton, Payne, Sargeant \& Seymour, 2009).

Our findings are in line with previous studies that showed the negative influence of poor communication and lack of integrated work in discharge planning (Atwal, 2002; Cheek \& Gibson, 2003; Connolly et al., 2009). In spite of health care leaders encouraging teamwork and collaboration (Nosbusch et al., 2010), a reluctance towards interdisciplinary communication and knowledge sharing between the discharge team and the ward staff was evident in our study. Some authors argue that interdisciplinary communication can be affected by role confusion and competing priorities (i.e. providing care versus organising care after discharge) (Atwal, 2002). Where some ward staff viewed discharge planning as being within the scope of their work, others did not have the same view. This is similar to that of Han et al. (2009) who found that hospital nurses did not view discharge planning as a core activity of their daily clinical work. It is also similar to that of Rhudy, Holland and Bowles (2010) who reported that registered nurses' role was limited to oversight when discharge facilitators where involved. Such nurses did not actively seek information about patients' discharge; instead they tried to resolve problems informally in order to speed up the discharge process and free up a bed in the ward. 


\section{Study limitations}

This was a small qualitative study carried out in one acute care trust in Eastern England, thus it is suggested that it should be repeated in other acute care settings. Qualitative research explores how a group of individuals experience a phenomenon under study, and hence, one of its limitations is the generalisability of the research outcomes. The findings should be treated cautiously and not generalised to the other acute care settings.

\section{Conclusion}

Nurses are socialised in a professional environment where patient autonomy is supported and healthcare provision is framed as holistic (Hau, 2003). If political and organisational factors do not allow nurses to practice nursing in a manner that meets their professional values and standards, then they are likely to experience moral distress. Our findings indicate that this is not a possible outcome, but rather the current state of affairs for nurses working in 'continuing healthcare' cases in England. Nursing practice has already been described as inflexible and bureaucratic (Efraimsson et al., 2004); a great deal of nurses' decision-making responsibilities have been transferred to physicians and other health committees, leaving nurses performing an administrative rather than a leading role in clinical decision-making. Nurses, alongside patients and family members, should have a greater role and involvement in the decision-making process around the care of the patient, and particularly in complex discharge cases, as they are likely to know the needs of the patients much better, compared to panels that have never met the patient before. By ensuring that nurses are involved in the decision-making process and their opinions 
are taken into account, it is likely that patients' experience of care will improve and that nurses' will experience less moral distress and hence, enjoy better levels of job satisfaction, as they could contribute to providing care to the patients and their families that meets their professional values and standards.

Reprioritising and increasing the availability of resources for discharge-related care in both the hospital and the community will allow the discharge facilitators to speed up the discharge planning process and it will release some of the pressure that they experience in their everyday clinical practice. In the long run, such investment will decrease healthcare costs, as patients will be discharged faster, the recruitment of agency nurses will be reduced and there will be more doctors, nurses and allied health professionals in the wards to care for the patients. Strengthening the interface of health and social care will contribute to decreasing the fragmentation of care and enhancing continuity of care. Comprehensive coverage of discharge planning should be included in the curricula at all levels of education for nurses, doctors and allied health professions working in the acute care setting (i.e. physiotherapists, OTs). Such training will enhance ward staffs' capabilities in complex discharge planning and contributed to release some of the pressure that many discharge facilitators' experience. Continuing professional development on complex discharge planning should become available in order to ensure that the complexities of the process will be addressed. Our findings offer a basis for further research on how other aspects of the complex hospital discharge planning process may contribute to nurses' experiencing moral distress. 


\section{References}

Armitage, S.K., \& Kavanagh, K.M. (1996). The discharge liaison nurse at the interface of hospital and community nursing services. International Journal of Nursing Practice, 2(4), 215221.

Atwal, A. (2002). Nurse's perceptions of discharge planning in acute health care: a case study in one British teaching hospital. Issues and Innovations in Nursing Practice, 39(5), 450-458.

Augustinsson, S., \& Petersson, P. (2015). On discharge planning: dynamic complex process uncertainty, surprise and standardisation. Journal of Research in Nursing, 20(1), 39-53. doi: $10.1177 / 1744987114564257$.

Bauer, M., Fitzgerald, L., Haesler, E., \& Manfrin, M. (2008). Hospital discharge planning for frail older people and their family. Are we delivering best practice? A review of the evidence. Journal of Clinical Nursing, 18, 2539-2546. doi: 10.1111/j.1365-2702.2008.02685.x

Braun, V., \& Clarke, V. (2006). Using thematic analysis in psychology. Qualitative Research in Psychology, 3(2), 77-101.

Chaboyer, W., Foster, M., Kendall, E., \& James, H. (2004). The impact of a liaison nurse on ICU nurses' perceptions of discharge planning. Australian Critical Care, 17(1), 25-32.

Chang, W., Goopy, S., Lin, C.C., Barnard, A., Liu, A., \& Han, C.Y. (2015). Registered nurses and discharge planning in a Taiwanese ED: A neglected issue? Clinical Nursing Research, 3. doi: $10.1177 / 1054773815584138$. 
Cheek, J., \& Gibson, T. (2003). Issues impacting on registered nurses providing care to older people in an acute care setting. Journal of Research in Nursing, 8(2), 134-149.

Chen, P. (2009). When nurses and doctors can't do the right thing. Retrieved February 17, 2016 from www.nytimes.com/2009/02/06/health/05chen.html.

Connolly, M., Grimshaw, J., Dodd, M., Cawthorne, J., Hulme, T., et al. (2009). Systems and people under pressure: the discharge process in an acute hospital. Journal of Clinical Nursing, $18(4), 549-558$.

Coombs, M., Long-Sutehall, T., Darlington, A.S., \& Richardson, A. (2015). Doctors' and nurses' views and experience of transferring patients from critical care home to die: A qualitative exploratory study. Palliative Medicine, 29(4), 354-362. doi: 10.1177/0269216314560208

Corley, M. C. (2002). Nurse moral distress: A proposed theory and research agenda. Nursing Ethics, 9(6), 636-650.

Corrigan, O., Georgiadis, A., Davies, A., Lane, P., Milne, E., et al. (2016). Insights into Hospital Discharge. A study of patient, carer and staff experience in Essex. Manuscript submitted for publication.

Currie, L., \& Watterson, L. (2008). Improving the safe transfer of care: A quality improvement initiative. Final Report. London: Royal College of Nursing.

Day, M.R., McCarthy, G., \& Coffey, A. (2009). Discharge planning: the role of discharge coordinator. Nursing Older People, 21, 26-31. 
Department of Health. (2000). The NHS plan. A Plan for Investment. A Plan for Reform. London: HMSO.

Department of Health. (2003). Community Care (Delayed Discharges etc.) Act (2003): Guidance for Implementation. London: Department of Health.

Department of Health. (2010). Ready to go? Planning the discharge and the transfer of patients from hospital and intermediate care. London: Department of Health.

Department of Health. (2012). Decision support tool for NHS continuing healthcare (revised). London: Department of Health.

Department of Health. (2012a). Fast track pathway tool for NHS continuing healthcare (revised). London: Department of Health.

Dow, J. (2009). Continuing healthcare - The story so far. Journal of Integrated Care, 17(4), 1215.

Effraimsson, E., Sandman, P.O., Hyden, L., \& Rasmussen, B.H. (2004). Discharge planning: 'fooling ourselves' - patient participation in conferences. Journal of Clinical Nursing 13, 562570.

Ekdahl, A.N., Linderholm, M., Hellstrom, I., Andersson, L., \& Friedrichsen, M. (2016). ‘Are decisions about discharge of elderly hospital patients mainly about freeing blocked beds?' A qualitative observational study. BMJ Open, 2. doi: 10.1136/bmjopen-2012-002027.

Epstein, E.G., \& Delgado, S. (2010). Understanding and addressing moral distress. The Online Journal of Issues in Nursing, 15(3). doi: 10.3912/OJIN.Vol15No03Man01. 
Epstein, E.G., \& Hamric, A.B. (2009). Moral distress, moral residue, and the crescendo effect. Journal of Clinical Ethics, 20(4), 330-342.

Fielding, N. (1993). Ethnography. In N. Gilbert (Ed.), Researching Social Life (pp. 154-171). London: Sage.

Gallagher, A. (2010). Moral distress and moral courage in everyday nursing practice. The Online Journal of Issues in Nursing, 16(2). doi: 10.3912/OJIN.Vol16No02PPT03

Gholizadeh, M., Delgoshaei, B., Gorji, H.A., Toram, S., \& Janath, A. (2016). Challenges in patient discharge planning in the health system of Iran: A qualitative study. Global Journal of Health Science, 8(6), 168-178.

Han, C.Y., Barnard, A., \& Chapman, H. (2009). Emergency department nurse's understanding and experience of implementing discharge planning. Journal of Advanced Nursing, 65(6), 12831292. doi: 10.1111/j.1365-2648.2009.04988.x.

Hanna, D. R. (2004). Moral distress: The state of the science. Research \& Theory for Nursing Practice, 18(1), 73-93.

Hau, W. (2003). Caring holistically within new managerialism. Nursing Inquiry, 11(1), 2-13. Health and Social Care Act (2012). Available at: http://www.legislation.gov.uk/ukpga/2012/7/contents/enacted (Accessed: 30 November 2015).

Hendy, P., Patel, J.H., Kordbacheh, T. Laskar, N., \& Harbord, M. (2012). In-depth analysis of delays to patient discharge: a metropolitan teaching hospital experience. Clinical Practice, 12, $320-323$. 
Ingleton, C., Payne, S., Sargeant, A., \& Seymour, J. (2009). Barriers to achieving care at home at the end of life: transferring patients between care settings using patient transport services. Palliative Medicine, 23, 723-730.

Jameton, A. (1993). Dilemmas of moral distress: Moral responsibility and nursing practice. AWHONNS Clinical Issues in Perinatal \& Womens Health Nursing, 4(4), 542-51.

Kable, A., Chenoweth, L., Pond, D., \& Hullick, C. (2015). Health professional perspectives on systems failures in transitional care for patients with dementia and their carers: a qualitative descriptive study. BMC Health Services Research, 15. doi: 10.1186/s12913-015-1227-z.

Lofland, J., \& Lofland, L.H. (1995). Analyzing Social Settings: A guide to Qualitative Observation and Analysis. ( $3^{\text {rd }}$ ed.) California: Wadsworth.

McCarthy, J., \& Deady, R. (2008). Moral distress reconsidered. Nursing Ethics, 15(2), 254-262.

McKenna, H., Keeney, S., Glenn, A., \& Gordon, P. (2000). Discharge planning: an exploratory study. Journal of Clinical Nursing, 9, 594-601.

NHS Confederation, (2012). Papering over the cracks: the impact of social care funding on the $N H S$, Issue 248. http://www.nhsconfed.org/ /media/Confederation/Files/Publications/Documents/papering-overcracks.pdf

Noble, H., \& Smith, J. (2015). Issues of validity and reliability in qualitative research. EvidenceBased Nursing, 18, 34-35. doi: 10.1136/eb-2015-102054. 
Nosbusch, J.M., Weiss, M.E., \& Bobay, K.L. (2010). An integrated review of the literature on challenges confronting the acute care staff nurse in discharge planning. Journal of Clinical Nursing, 20, 754-774. doi: 10.1111/j.1365-2702.2010.03257.x.

O’Reilly, K. (2005). Ethnographic Methods. London: Routledge.

Phillips, C.O., Wright, S.M., Kern, D.E., Singa, R.M., Shepperd, S., \& Rubin, H.R. (2004). Comprehensive discharge planning with postdischarge support for older patients with congestive health failure: a meta-analysis. JAMA, 291(11), 1358-67.

Preen, D.B., Bailey, B.E., Wright, A., Kendall, P., Phillips, M. et al. (2005). Effects of a multidisciplinary, post-discharge continuance of care intervention on quality of life, discharge satisfaction, and hospital length of stay: a randomized controlled trial. International Journal for Quality Health Care, 17(1), 43-51.

Rhudy, L., Holland, D.E., \& Bowles, K.H. (2010). Illuminating hospital discharge planning: staff nurse decision making. Applied Nursing Research, 23, 198-206. doi:10.1016/j.apnr.2008.12.003.

Rose, M., \& McCarthy, G. (2009). Discharge planning: the role of the discharge coordinator. Nursing Older People, 21(1), 26-31.

Royal College of Nursing, (2008). Defending dignity: Challenges and opportunities for nursing. London: Royal College of Nursing. Retrieved from www.rcn.org.uk/_data/assets/pdf_file/0011/166655/003257.pdf.

Schluter, J., Winch, S., Holzhauser, K., \& Henderson, A. (2008). Nurses' moral sensitivity and hospital ethical climate: A literature review. Nursing Ethics, 15(3), 304-321. 
Sporrong, S.K., Hoglund, A.T., Hansson, M.G., Westerholm, P., \& Arnetz, B. (2005). "We are white coats whirling round"--moral distress in Swedish pharmacies. Pharmacy World \& Science, 27(3), 223-229.

Taxis, K., \& Barber, N. (2003). Ethnographic study of incidence and severity of intravenous drug errors. $B M J, 326$. doi: $10.1136 / \mathrm{bmj} .326 .7391 .684$

The Health Foundation, (2015). http://www.health.org.uk/sites/default/files/Spending-ReviewNuffield-Health-Kings-Fund-December

2015_spending_review_what_does_it_mean_for_health_and_social_care.pdf (Accessed in April 2016).

Venkatasalu, M.R., Clarke, A., \& Atkinson, J. (2015). 'Being a conduit' between hospital and home: stakeholders' views and perceptions of a nurse-led Palliative Care Discharge Facilitator Service in an acute hospital setting. Journal of Clinical Nursing, 24, 1676-1685. doi: 10.1111/jocn.12769.

Waring, J., Marshall, F., Bishop, S., Sahota, O., Walker, M. et al. (2014). An ethnographic study of knowledge sharing across the boundaries between care processes, services and organisations: the contributions to 'safe' hospital discharge. Health Services and Delivery Research, 2(29). doi: 10.3310/hsdr02290

Wong, E.L.Y., Yam, C.H.K., Cheung, A.W.L., Leung, M.C.M., Chan, F.W.K. et al. (2011). Barriers to effective discharge planning: a qualitative study investigating the perspectives of frontline healthcare professionals. BMC Health Services Research, 11(242). doi: 10.1186/14726963-11-242. 
Figure 1. Complex care pathways

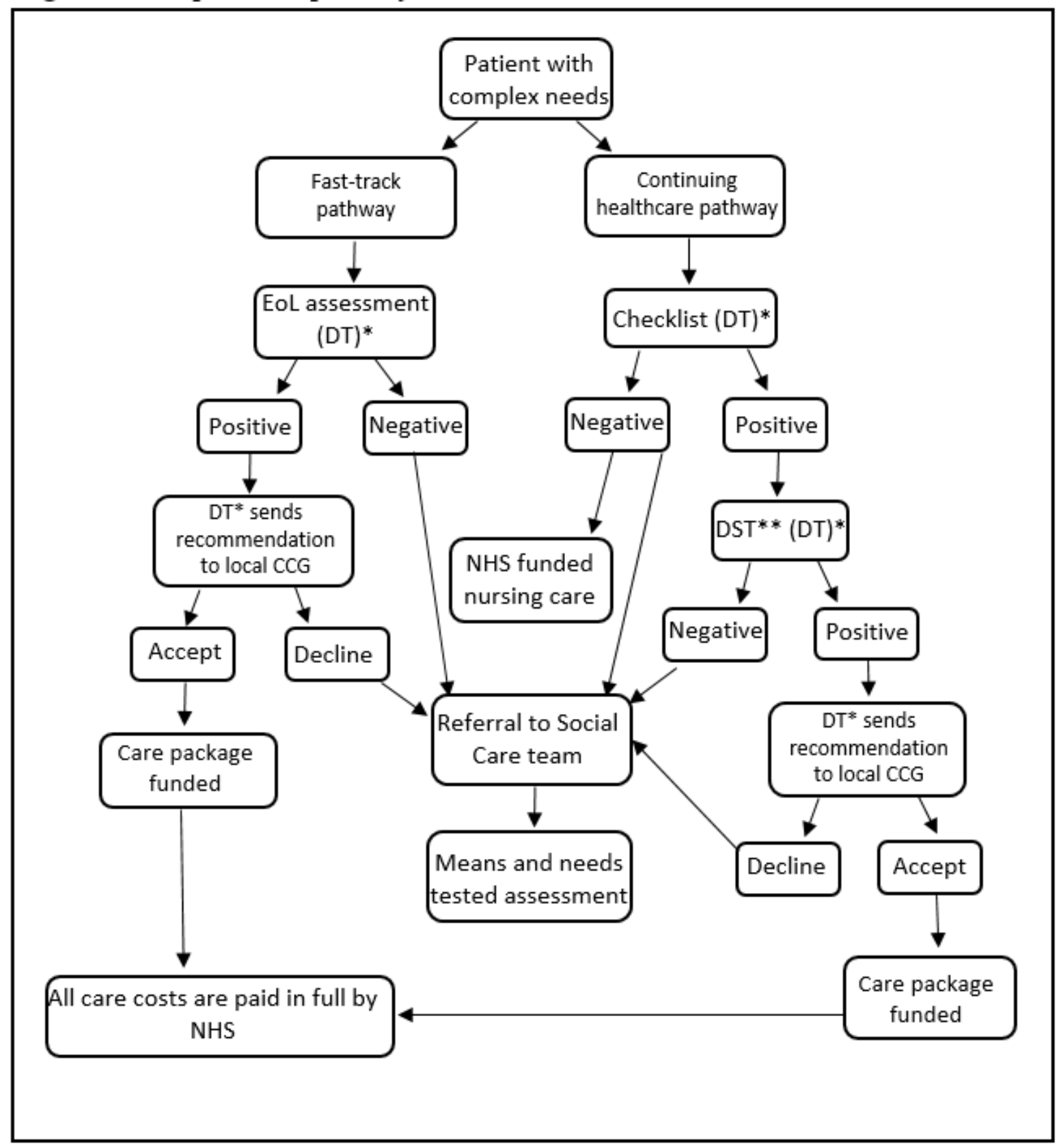

*DT: Discharge team, **DST: Decision Support Tool 
Table 1: Participants' details

\begin{tabular}{|c|c|c|}
\hline Participant & Gender & $\begin{array}{c}\text { Years of experience in } \\
\text { complex discharge planning }\end{array}$ \\
\hline DF health care 1 & Female & 1 \\
\hline DF health care 2 & Female & 6 \\
\hline DF health care 3 & Female & 1.5 \\
\hline DF health care 4 & Female & 5 \\
\hline DF social care 1 & Female & 1 \\
\hline DF social care 2 & Female & 7 \\
\hline DF social care 3 & Female & 1 \\
\hline Consultant (elder care) & Male & 26 \\
\hline DF: Discharge facilitator & & \\
\hline
\end{tabular}


Table 2: Interview topic guide

Experience of working on discharge

- $\quad$ Experience of collaborating with other staff

- $\quad$ Experience of liaising with local health and social care providers

- $\quad$ Experience of communication with patients and with carers

Challenges and solutions working towards a seamless discharge

- Challenges and solutions experienced in relation to working with local health and social care providers

- $\quad$ Challenges and solutions experienced in relation to interaction with patients and their carers

- Challenges and solutions experienced in relation to working with other members of staff 
Table 3: Phases of thematic analysis (taken from Brown and Clarke (2006) and adopted for this study)

1. Familiarising yourself with your data AG reading and re-reading the data, noting

2. Generating initial codes Coding features of the data relevant to participants' understandings of the complex discharge process in a systematic fashion

3. Searching for themes Collating codes that referred to the complex discharge process into potential themes,

4. Reviewing themes Checking the themes in relation to the coded extracts and the entire data set,

5. Defining and naming themes

Ongoing analysis to refine the specifics of each theme, and the overall story the analysis tells; generating clear definitions and names for each theme. AG followed Braun and Clark's guidelines on internal 6. Producing the report Selection of vivid, compelling extracts of examples; final analysis of selected extracts; 